\title{
An Innovative Adapter to use Smartphone flashlight as a light source for endoscopy in emergency and LMICs
}

\author{
Yassine Baskoun ${ }^{1}$, Mustafa El Alami ${ }^{2}$, Salah Dine Qanadli ${ }^{3}$, Moha Arouch $^{4}$, Mohamed Taouzari ${ }^{5}$ \\ ${ }^{1}$ Laboratory of Engineering, Mechanics, Industrial Management and Innovation, Faculty of Science and \\ Technology, University Hassan 1st, MA 26000 Settat, Morocco, y.baskoun @uhp.ac.ma \\ ${ }^{2}$ Laboratory of Engineering, Mechanics, Industrial Management and Innovation, Faculty of Science and \\ Technology, University Hassan 1st, MA 26000 Settat, Morocco, mustafa.elalami@ gmail.com \\ ${ }^{3}$ Laboratory of Engineering, Mechanics, Industrial Management and Innovation, Faculty of Science and \\ Technology, University Hassan 1st, MA 26000 Settat, Morocco, m.arouch @ uhp.ac.ma \\ ${ }^{4}$ Cardio-Thoracic and Vascular Unit, Department of Radiology, University Hospital of Lausanne, Bugnon 46, \\ 1011 Lausanne, Switzerland, Salah.Qanadli@ chuv.ch \\ ${ }^{5}$ Laboratory LISA, National School of Applied Sciences Berrechid, University Hassan 1st, Settat, Morocco, \\ m.taouzari@uhp.ac.ma,
}

\begin{abstract}
This article describes the feasibility of using smartphones as an alternative light source in endoscopic procedures by comparing it to conventional light sources. Therefore, we used an adapter designed and printed in $3 \mathrm{D}$, combined with an iPhone 6S, ear endoscope L. 50mm diam. $4 \mathrm{~mm} 0^{\circ}$ and a cardboard as dark anterior. Tests have shown that the illumination is adequate and sufficient, and the results obtained are satisfactory. As a conclusion, this adapter and method finds its place in clinical emergency situations and when endoscopy tower or portable light source might not be available especially in low- and middle-income countries (LMCIs).
\end{abstract}

Key words : Smartphone flashlight, light source endoscopy; 3D print adapter, LMCIs, MHealth, Telemedicine.

\section{INTRODUCTION}

From the time of Hippocrates, the Romans Figure 1(a), Babylon and Egyptians to the 16th century, viewing the inside of the human body was always a challenge for doctors. The obstacle to endoscopy was the illumination. We tried several often inadequate methods and techniques, before designing the light sources that we use today at current endoscopy systems such as ambient sunlight, candles, mirrors, lenses and lamps, up to LED and XENON lights. Giulio Cesare Aranzi (1530-1589) let a ray of sunlight penetrate through the slit of a shutter, which he concentrated with a bottle filled with water in a dark room. In 1806 Philipp Bozzini imagined the "lichtleiter" or "light conductor" grouping a lantern (wax candle) and a series of metal tubes provided with concave mirrors Figure 1(b). Then, in 1840 Daniel Colladon and Jacques Babinet created the "light fountain". In 1853, Antonin Jean Desormeaux (1815-1894) considered the father of endoscopy, was the first to visualize the bladder with a tube lit by an oil lamp basing this research on the work of BOZZIN Figure 1(c). 1879 Maximilian Carl-Fredrich Nitze (1848-1906) used Edison's miniaturized electric lamp to build the first cystoscope, Figure 1(d). 1917 Rudolf Schindler, from the work of Lang, built with the help of the Wolf company the first semi-flexible gastroscope containing a miniature lamp and the lens prism at the distal end Figure 1(e). 1932, Heinrich Lamm demonstrated light transmission by glass fibers. In 1954, HAROLD HOPKINS and Narinder Singh Kapany were working on fiber optic light cables and then in partnership with KARL STORZ created the modern endoscope that we use nowadays Figure 1(f), and starting from the poor images obtained due to poor light transmission, used optical fibers for superior illumination using a simple lamp. 1963 John Scarff uses the luminous fibers with an external light source for the ventriculoscopy. Also in 1963, Gerard Guiot and Jacques Vulmiere developed an external light source (cold light generator). More efficient and miniaturized systems for providing fiber optic lighting in conjunction with CCD camera technology were developed by Welch Allyn in 1984 [1]-[3]. 


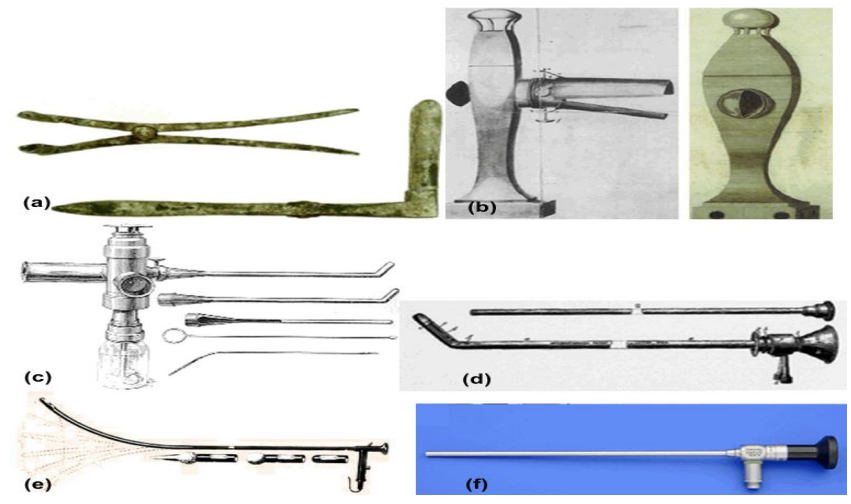

Figure 1: Endoscope development

In the general light source offers many features, but it still suffers from disadvantages in terms of the implementation and cost. It is cumbersome and stationary that is not conducive to remote locations such as emergency departments or patient wards or other area outside hospitals where there is no electricity, especially in low- and middle-income countries (LMICs). Smartphones are now increasingly used in the medical field due to their price, mobility, high processing power, and the development of novel health-care applications[4],[5] and especially endoscopy [6], [7].

Lack of light sources, power outages, or unexpected lamp failures during endoscopic procedures is time-consuming and therefore can endanger the health of the patient in question. Some studies have shown the possibility of using the flashlight of smartphones as a light source. Avidan et al. Figure 2(a) used the "Assistive Light Widget" for Android to complete a direct laryngoscopy being interrupted due to the broken laryngoscope lamp [8]. Robinson et al. Figure 2(b) demonstrated the use of an iPhone $5 \mathrm{~S}$ as a light source for flexible cystoscopes in case of failure or unavailability [9]. Milner et al. Figure 2(c) used the iPhone 5S smartphone as an immediate light source for flexible naso-fibroscopy and the results showed that the illumination is better than portable rechargeable sources [10]. Deshmuckh et al. Figure 2(d) successfully performed a thoracoscopy procedure after a malfunction of two light sources using the flashlight of an iPhone 5S and thus concluded that the light was comparable to the conventional source [11], [12]. Ray et al. Figure 2(e) used a smartphone flashlight during a tracheostomy after the light source suddenly stopped during the procedure [13]. Davidson et al. Figure 2(f) demonstrated the feasibility of using the smartphone for short cystoscopy in poor or developing countries (LMICs) after the light source lamp went out in the absence of spare with an iPhone 6 that generated enough illumination to do the exam [14]. By comparing conventional light sources, namely stryker 8000 and storz 1130103 and galaxy S6 and S7 smartphones, and iPhone 4, 6, 8 and X; Butler et al. Figure 2(g) concluded the feasibility of using the flashlight for flexible laryngoscopy [15].

The structure of this work is as follow: The first section focuses on the working principle, designing and discussion.
The second section is about a 3D design prototype. The last section gives the comparison with alternative devices. Finally, a conclusion is given.

\section{DESIGN AND OPERATION OF THE ADAPTER}

The 2D design of the adapter subject of this work shown in Figure 3(a) is made with CAD software, and their components are shown in the 3D design Figure 3(b). We fix element 1 on element 4 and we use element 3 to block element 1 from turning on its axis, then we put the smartphone in element 4 to fix and center the flashlight with element 1 . Then we adjust with element 2 which allows moving element 1 horizontally in both directions for more precision. Then we insert the light cable (source side) in element 1 and we turn on the flashlight.

(we adjust the brightness as needed).

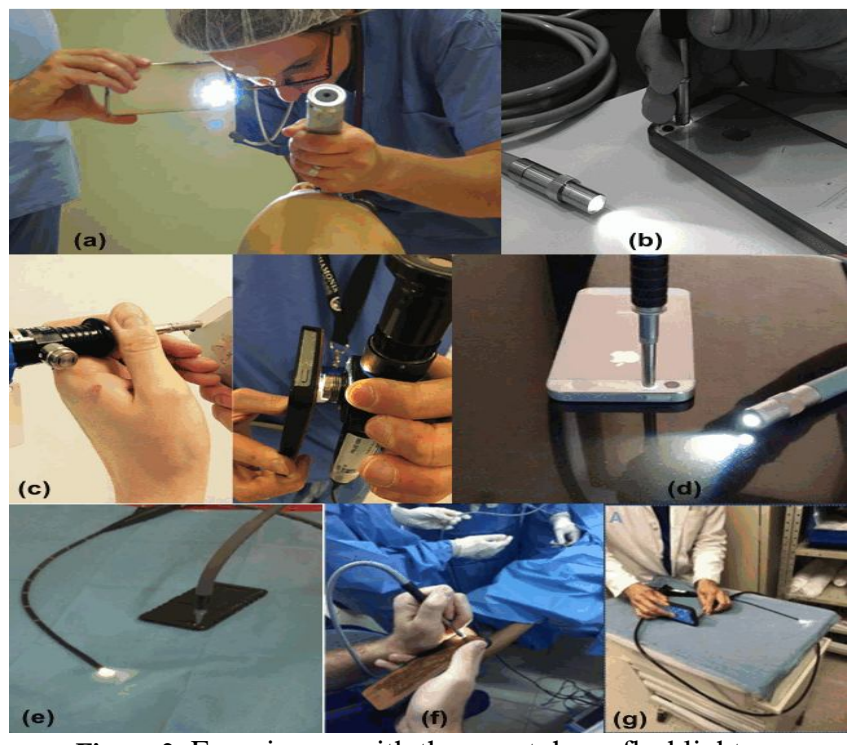

Figure 2: Experiences with the smartphone flashlight

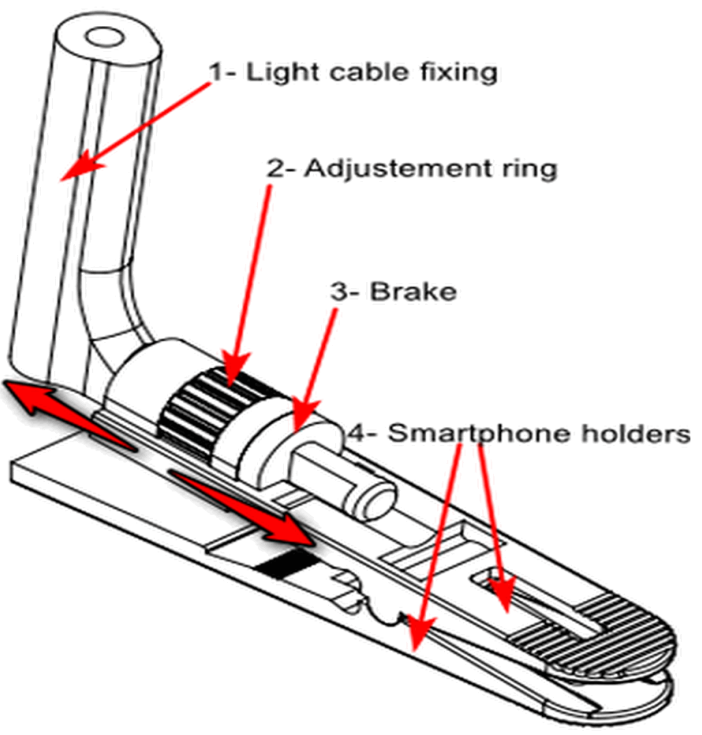

Figure 3(b): 3D design 


\section{TEST AND RESULTS}

To validate the proposed adapter, we used the prototype printed with a 3D printer Figure 4, the USAF-1951 as an endoscopic target put in a cardboard simulating a dark anterior and an ear endoscope L. 50mm diam. $4 \mathrm{~mm}$ Mink 0 ${ }^{\circ}$. We did two tests, one with IPhone $6 \mathrm{~s}$ and the other with a 150W halogen light source WOLF 4015 LICHTPROJEKTOR Figure 5.

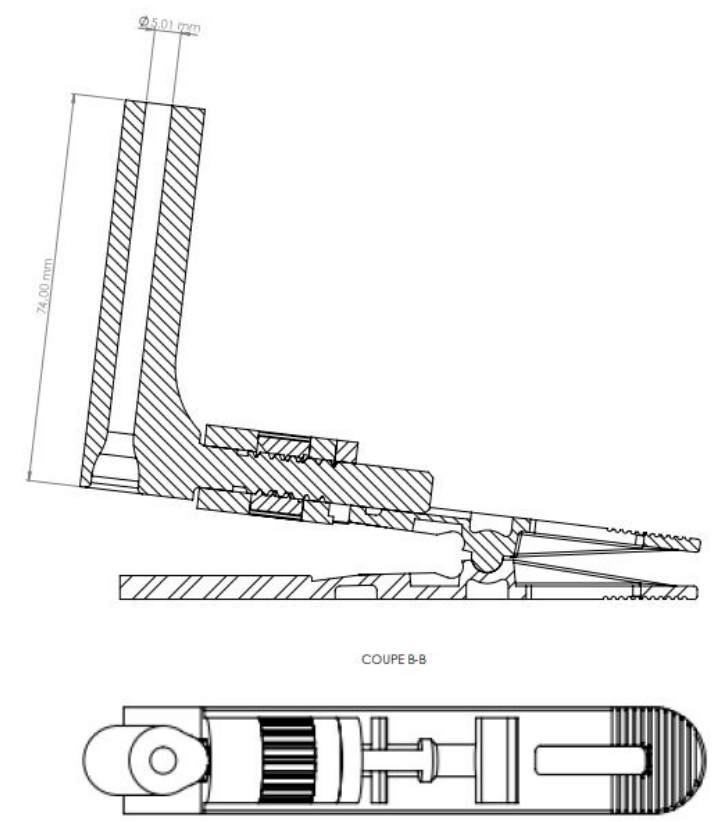

The endoscopy photos are taken with a Samsung Galaxy Tab A6. The results obtained with the two light sources are shown in Figure 6, and after comparison we see that the image obtained with the Smartphone flashlight Figure 6(a) is similar but slightly higher than with the WOLF 4015 Figure 6(b), because of the characteristic TRUETONE in the flashlight of the IPhone 6S. The illumination of the two sources is measured with the application LuxMeter "developed by Seolgi .co" are shown in the Figure 7.
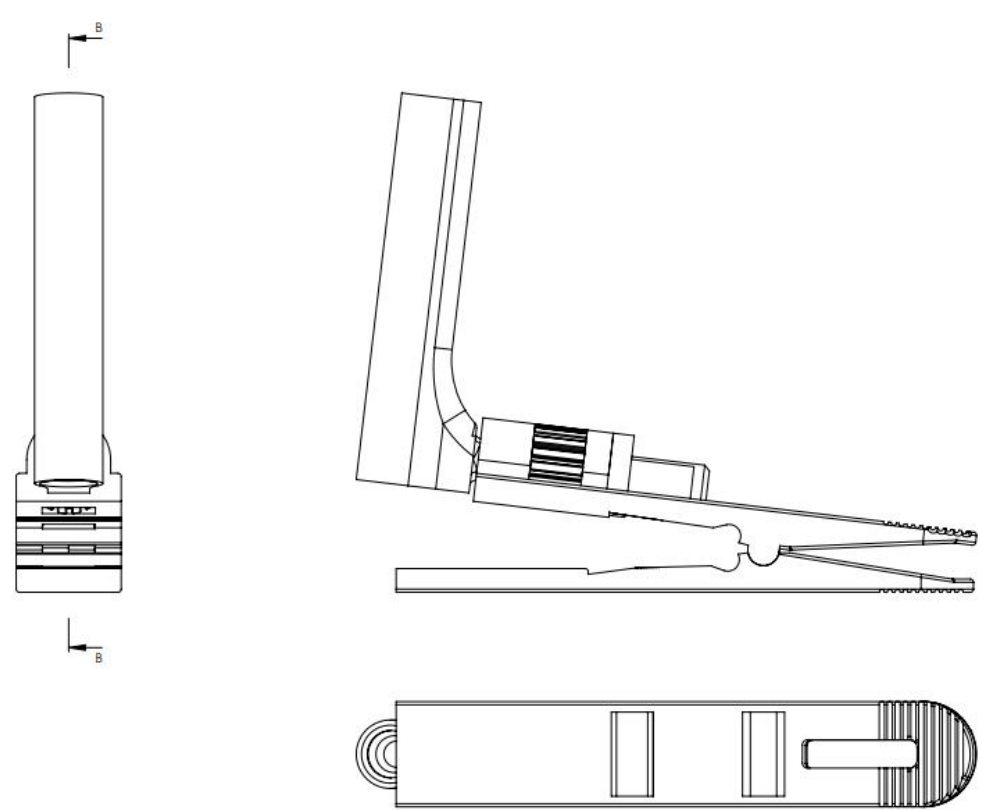

Figure 3(a): 2D design

The comparison between the proposed adapter and the other methods proposed by the studies cited in this work are mentioned in the table Table 1.

Table 1: Comparison with other studies

\begin{tabular}{|c|c|c|}
\hline Device & Advantage & Inconvenient \\
\hline $\begin{array}{l}\text { Proposed } \\
\text { adaptor }\end{array}$ & $\begin{array}{l}\text { Resolve the emergency } \\
\text { No need to an assistant } \\
\text { to hold the cable with } \\
\text { the flashlight } \\
\text { Centring flashlight and } \\
\text { fiber optic cable } \\
\text { Lightweight } \\
\text { Transportable }\end{array}$ & None \\
\hline Avidan [8] & Resolve the emergency & $\begin{array}{c}\text { not fixed, } \\
\text { not centered, } \\
\text { need assistant }\end{array}$ \\
\hline Robinson [9] & Resolve the emergency & $\begin{array}{c}\text { not fixed, } \\
\text { not centered, } \\
\text { need assistant }\end{array}$ \\
\hline Milner[10] & Resolve the emergency & $\begin{array}{c}\text { not fixed, } \\
\text { not centered, } \\
\text { need assistant }\end{array}$ \\
\hline $\begin{array}{c}\text { Deshmukh } \\
{[11],[12]}\end{array}$ & Resolve the emergency & $\begin{array}{c}\text { not fixed, } \\
\text { not centered, } \\
\text { need assistant }\end{array}$ \\
\hline
\end{tabular}

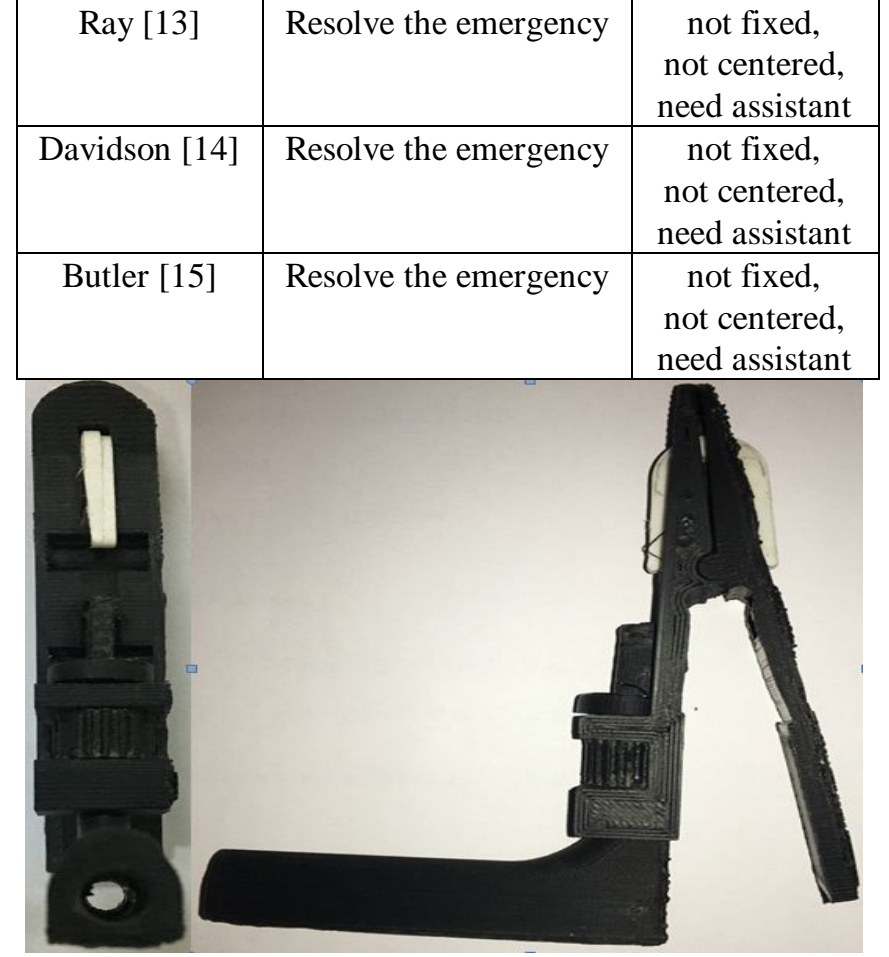

Figure 4: front and left view of the 3D printed adapter 


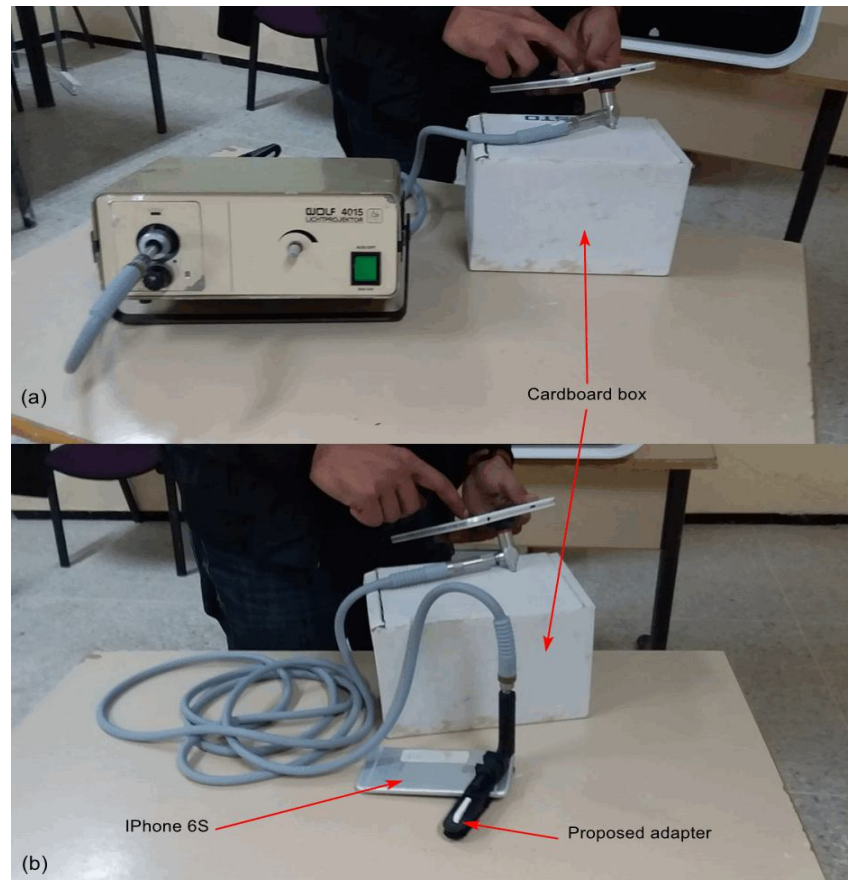

Figure 5: Tests: (a) with WOLF 4015 (b) with IPhone 6S

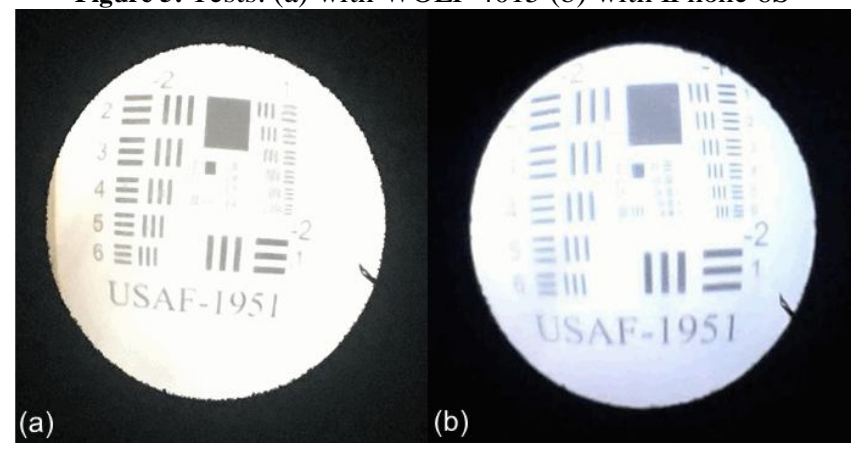

Figure 6: Results: (a) with smartphone (b) with WOLF 4015

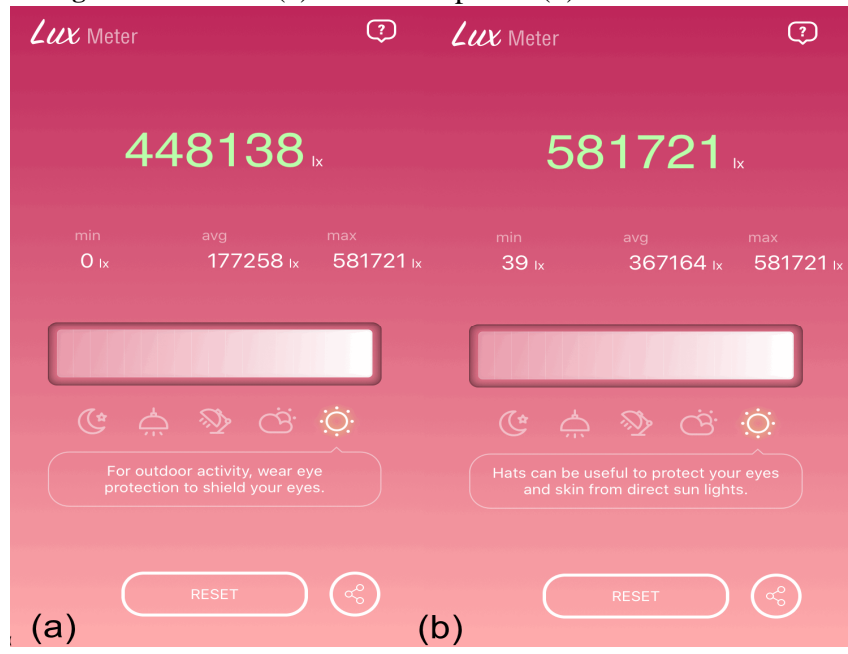

Figure 7: (a) Smartphone flash light (b) WOLF 4015

\section{CONCLUSION}

The use of smartphones in medicine has enormously helped practitioners and patients especially in emergencies in lowand middle-income countries LMICs because of their availability, their price as well as their continuous development. In this work we have proven the use of the smartphone's flashlight as a light source for endoscopy with the 3D printed adapter and its usefulness by comparing it to the other experiences already mentioned, by eliminating the need for an assistant to fix and center the light cable with the flashlight, its weight and small size facilitating its mobility. Thus this adapter finds its place in emergency cases (unexpected breakdown of the light source, outside hospitals ...), caravans, distant health facilities with limited resources and LMICs to give adequate and sufficient illumination to complete endoscopic procedures.

\section{ACKNOWLEDGEMENT}

The authors would like to thank the HealthCare Foundation (HCAF) Lausanne, Switzerland for the support and funding to achieve this research work.

\section{REFERENCES}

1. G. Zada, C. Liu, and M. L. J. Apuzzo. 'Through the looking glass': Optical physics, issues, and the evolution of neuroendoscopy, World Neurosurg., vol. 79, no. 2 SUPPL., pp. S3-S13, 2013. https://doi.org/10.1016/j.wneu.2013.02.001

2. O. H. Ahmed, S. Marcus, R. A. Lebowitz, and J. B. Jacobs. Evolution in Visualization for Sinus and Skull Base Surgery: From Headlight to Endoscope, Otolaryngologic Clinics of North America, vol. 50, no. 3. W.B. Saunders, pp. 505-519, 01-Jun-2017.

3. J. Guerre. Histoire de l'endoscopie digestive, médecine/sciences, vol. 15, no. 10, p. 1135, Aug. 1999. https://doi.org/10.4267/10608/1227

4. S. Haritha, Y. Anusha, P. S. Anivash, and S. V Manikanta. MINI DOCTOR, Int. J. Emerg. Trends Eng. Res., vol. 3, no. 10, pp. 349-351, 2015.

5. E. B. Panganiban, Microcontroller-based Wearable Blood Pressure Monitoring Device with GPS and SMS Feature through Mobile App, Int. J. Emerg. Trends Eng. Res., vol. 7, no. 6, pp. 32-35, Jun. 2019. https://doi.org/10.30534/ijeter/2019/02762019

6. Taouzari Mohamed, Moha Arouch, Y. Baskoun, A. Mouhsen, H. Aziz, and F. F. Hicham. Adaptateur ajustable avec les smartphones et les cameras numeriques pour les applications endoscope et biomédicale, Morocco patent MA37682 A1, 23 December 2014.

7. Y. Baskoun, S. D. Qanadli, M. Arouch, M. Taouzari, M. Elalami, and A. Hraiba, Development of a new diagnostic tool in the field of endoscopy and telemedicine applications, vol. 914. Springer International Publishing, 2019.

8. A. Avidan, R. Shaylor, and P. D. Levin. Smartphone assisted laryngoscopy: A new technique to overcome light failure in a laryngoscope, Anesthesia and Analgesia, vol. 117, no. 5. pp. 1262-1263, Nov-2013.

9. A. Robinson, B. Lovell-Viggers, and $\mathrm{N}$. Arumainayagam. An emergency back-up light source 
for flexible cystoscopy can be found in most of our pockets, Ann. R. Coll. Surg. Engl., vol. 99, no. 1, pp. 94-95, Jan. 2017.

https://doi.org/10.1308/rcsann.2016.0233

10. T. D. Milner, J. Montgomery, and M. Stewart. Flexible nasendoscopy: the use of smartphones as an immediate light source, Clinical Otolaryngology, vol. 43, no. 1. pp. 399-400, Feb-2018.

11. V. Deshmukh. Use Of Smartphone In-Built Flashlight As Light Source In Bronchoscopy Or Thoracoscopy, Am. J. Respir. Crit. Care Med., vol. 195, no. A45, 2017.

12. V. Deshmukh and S. Iyer. Use of Smartphone Flashlight in Bronchoscopy and Thoracoscopy, J. Bronchology Interv. Pulmonol., vol. 26, no. 1, pp. e1-e2, Jan. 2019.

13. A. Ray, Bharath, S. Sinha, and S. S. Paul. A smartphone comes to the rescue during tracheostomy, Critical Care, vol. 23, no. 1. Critical Care, p. 25, 24-Dec-2019. https://doi.org/10.1186/s13054-019-2324-x

14. J. R. Davidson, K. Ford, N. Ade-Ajayi, and A. Paul. Improvise, Adapt, Overcome: mobile phone LED used as a light source for cystoscopy and resection of posterior urethral valves in a low-cost setting, J. Pediatr. Urol., vol. 15, no. 1, pp. 85-86, Feb. 2019.

15. J. J. Butler, S. F. White, C. W. M. Myint, and M. W. Groves. The Feasibility of Utilizing Smartphone Flashlights as an Alternative Endoscopic Light Source in Emergency Situations, Ear, Nose Throat J., pp. 1-6, Aug. 2019.

https://doi.org/10.1177/0145561319862212 